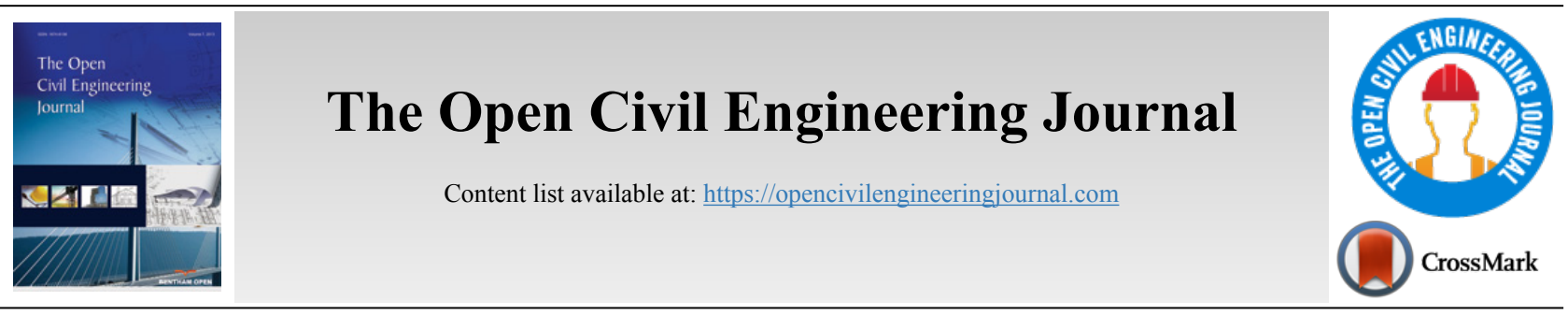

RESEARCH ARTICLE

\title{
Performance of Shallow Building Foundations under Infrequent Rainfall Patterns at Al-Madinah, Saudi Arabia
}

\author{
Qazi U. Farooq ${ }^{1}$ and Muhammad T. Naqash ${ }^{1, *}$ \\ ${ }^{1}$ Department of Civil Engineering, Islamic University of Madinah, Madinah, Saudi Arabia
}

\begin{abstract}
:
Objective:

This research mainly emphasizes the sustainability of midrise buildings in the holy city of Al-Madinah under varying rainfall patterns.

Background:

Western Saudi Arabia is usually a dry region, and most of the buildings are designed considering unsaturated soil conditions. However, highintensity unexpected rainfall events have been observed in recent times. This scenario alters the soil moisture conditions and exhibits a risk to the structural stability.

\section{Methods:}

In this study, Madinah Al-Munawara soil conditions are considered to analyse the isolated shallow foundation system. Finite element models are generated for dry and wet soil conditions by using the COMSOL Multiphysics program. The numerical analysis results indicate the possibility of higher settlements under saturated conditions. Simple 1-D experimental element model tests have also been conducted to analyze the effects of the moisture change on the pre-loaded shallow foundations.

Results:

The experimental results are qualitatively compared with numerical models to observe soil moisture's overall effects on the substructure. The research will contribute to the safety of existing structures and recommend parameters for future design projects.

\section{Conclusion:}

Shallow foundations on loose granular soils are vulnerable to moisture variations, and geotechnical conditions are critical to incorporate in the prospective design projects considering the changing climatic conditions.
\end{abstract}

Keywords: Infrequent rainfall patterns, Shallow foundations, Water infiltration, Foundation settlement, Soil relative density, Groundwater table.

\begin{tabular}{|l|c|c|c|}
\hline Article History & Received: November 5, 2020 & Revised: January 28, 2021 & Accepted: February 16, 2021 \\
\hline
\end{tabular}

\section{INTRODUCTION}

The water content in the soil plays a very vital role in determining its strength and deformation characteristics. The engineers involved in the substructure design have future challenges regarding serviceability under varying climate patterns. In the last two years (2018 - 2019) Madinah region of Saudi Arabia's kingdom received unexpected high rainfall, demonstrating the climatic change. There can be changes in soil properties resulting from the changing moisture conditions

\footnotetext{
Address correspondence to this author at Department of Civil Engineering, Islamic University of Madinah, Madinah, Saudi Arabia; Tel: +966-56-9211-879; E-mail: tayyab@iu.edu.sa
}

and groundwater table. The shallow foundations are particularly vulnerable since moisture penetrations can easily reach the influence zone. Building and infrastructure damage due to soil moisture occurs when differential movements exceed the codes' allowable limit. Therefore, at locations where uniform vertical settlement dominates, buildings often move vertically with the subsiding ground surface and cause slight damage. In contrast, when excessive differential deformation occurs, such structures are more prone to damage and require detailed investigations. The isolated footing system is generally constructed on the nominal bearing capacity of soil at a shallow depth for the Mid-rise buildings, having a considerable applied load. In such cases, the introduction of moisture in the soil 
makes it soft, and the foundation supporting strata might undergo excessive settlement. Lost in shear strength will be another possibility, resulting in excessive stability risk, and therefore, causing partial or full damage to the foundation system or the superstructure. The damage to the residential buildings in urban Surabaya, Indonesia, has been reported due to moisture-induced soil softening [1]. Shahriar et al. conducted laboratory investigations on sandy soil using various footing shapes, revealing a significant increase in the settlement due to soil saturation [2]. Several criteria for damage risk assessment are described in the literature [3, 4]. The settlement (downward movement of the ground surface) will occur during groundwater lowering and rising; heave (upward movement of the ground surface) in swellable soils is another possibility associated with the groundwater table. The potential degree of building damage due to ground movement caused by urban tunnel construction has been predicted by Mair et al. [5]. The risk categories versus the maximum settlement of buildings are summarized in Table $\mathbf{1}$.

Table 1. Tentative limits of building settlement and the tilt for damage risk assessment.

\begin{tabular}{|c|c|c|c|}
\hline $\begin{array}{c}\text { Risk } \\
\text { Category }\end{array}$ & $\begin{array}{l}\text { Maximum } \\
\text { Settlement } \\
\quad(\mathrm{mm})\end{array}$ & $\begin{array}{c}\text { Building } \\
\text { Tilt }\end{array}$ & Anticipated Effects \\
\hline Negligible & $<10$ & $<1 / 500$ & Superficial damage unlikely \\
\hline Slight & $10-50$ & $\begin{array}{l}1 / 500- \\
1 / 200\end{array}$ & $\begin{array}{c}\text { Possible superficial damage, } \\
\text { unlikely to have structural } \\
\text { significance }\end{array}$ \\
\hline Moderate & $50-75$ & $\begin{array}{c}1 / 200- \\
1 / 50\end{array}$ & $\begin{array}{c}\text { Expected superficial damage } \\
\text { and possible structural } \\
\text { damage to buildings; } \\
\text { possible damage to rigid } \\
\text { pipelines }\end{array}$ \\
\hline Severe & $>75$ & $>1 / 50$ & $\begin{array}{c}\text { Expected structural damage } \\
\text { to buildings and expected } \\
\text { damage to rigid pipelines or } \\
\text { possible damage to other } \\
\text { pipelines }\end{array}$ \\
\hline
\end{tabular}

Changes in soil water content might cause excessive settlement due to which the foundations lose their structural integrity. Groundwater table fluctuations change the overall effective and total stress conditions of the foundation supporting strata. This situation can present a risk related to ground settlement and stability of excavations [6]. The performance of the studied shallow foundations using slip line theory, while also considering suction effects, showed that the soil suction can significantly affect the bearing capacity of the footings [7]. Since soil suction depends on the degree of saturation, the water infiltration in the foundation supporting strata can imbalance the static equilibrium. An experimental study conducted on the infiltration of water in civil engineering structures showed that the electronic sensor can be effectively used for the real-time monitoring of water infiltration in sand and concrete [8]. Fine soils are usually more vulnerable to moisture variations and may swell on the absorption of moisture. Numerical modeling coupled with experimental calibration has been done to observe shallow foundations' construction functionality on vulnerable fine soils. The complex swell behaviors of clayey soil have been simplified by applying the elastic solution. The study considered the moisture variation along with the classical strength and deformation characteristics [9]. Semi-analytical tools can also be utilized to get an overall idea about the collapse settlement in soils due to water inundations [10]. Experimental studies on settlement and rotation evaluations of shallow foundations were compared with the numerical models considering soil and foundation as macro elements, whilst deformations were taken as generalized strain variables. The model results were in fair comparison with the experimental data [11].

A study conducted based on insurance claims due to foundation problems in the U.K. designates an increase in the number of insurance claims concerning climate change and rainfall patterns. However, the study lacks analytical conclusions, and the topic can be further explored [12]. Shallow building foundations are usually constructed above the groundwater table in humid climatic zones, considering the probability of seasonal fluctuations; hence, the load-bearing soil mostly remains unsaturated. The elastoplastic MohrCoulomb model can describe the mechanics of soil under unsaturated conditions [13]. Mohr-Coulomb model has been adopted to evaluate the pile-raft foundation on loose granular soils of Saudi Arabia using the geomechanics module of the COMSOL Multiphysics program [14]. Cement treatment has been contemporarily applied to improve the geotechnical conditions for shallow foundations. However, the moisture content present in the soil also affects cement treatment application [15]. The reliable classical solution is to use deep foundations as reinforced concrete piles or shallow raft footing, but these options are uneconomical for a limited budget project.

Rainwater infiltration into the natural ground is a complex phenomenon and depends upon many factors, such as soil properties, precipitation intensity, and boundary conditions [16]. One of these parameters is the initial soil moisture; infiltration usually decreases with an increase in moisture content, depending upon the hydraulic field gradients [17]. Since shallow foundations, including rafts, usually support low and mid-rise buildings, the foundation supporting soil strata is located few meters below the natural ground level and can be easily affected by rainfall infiltration. In this context, the dry soil conditions of Madinah Al Munawara have a higher tendency of water absorption. Hence, the behavior of substructure under changing climatic conditions of the city is required to be analyzed in detail for potential risk assessment. This theme is the key narrative of this study. Since soil properties and boundary conditions mostly remain constant at a particular site, consequently, only moisture conditions are varied in the study. The research outcome can be applied to any arid climatic zone with sandy soil conditions and increasing rainfall events. If the soil behavior under altering moisture conditions is adequately assessed, the simple isolated foundation system can safely be placed by using classical geotechnical techniques.

\section{GEOLOGY AND PRECIPITATION}

Al-Madinah region is located on the Arabian Peninsula western part, and geologically, located on the Arabian plate. 
The region mostly consists of basaltic rocks, while the southern hills of the city are made up of volcanic ash, which dates back to the Paleozoic Era. The city is surrounded by several mountains; Madinah is situated on a plateau at the junction of the three valleys and several green areas exist along with a dry mountainous region. The elevation of the city is approximately 620 meters and there are many volcanic rocks in the surrounding. The impervious layers and confined aquifers exist in some localities. Historically, there was continuous subsidence in the groundwater table, however, recently the groundwater is reported to be rising in urban areas. The phreatic aquifer lies well below the influence zone of shallow foundations with an average depth of $36.6 \mathrm{~m}$ in the residential areas $[18,19]$.
Madinah Al Munawara receives limited precipitation in the form of rain, mostly between November and May. The average data of precipitation for the last 6years is shown in Fig. (1). The weather data is taken from world weather online [20]. Usually, there are fewer than 6 rainy days a month.. From June to September, the peak summer season is very dry, with July receiving no rainfall in the last six years.

The recent years of data are further explored. The chart showing the number of rainy days for each year (last 12 years) is presented in Fig. (2), whereas, Fig. (3) shows the total amount of rainfall against each year from 2014 to 2019. It can be seen from Fig. (2) that 2015, 2018, and 2019 have more than 30 rainy days; the other years are relatively dry.

Fig. (1). Average precipitation in Madinah in last 5 years.

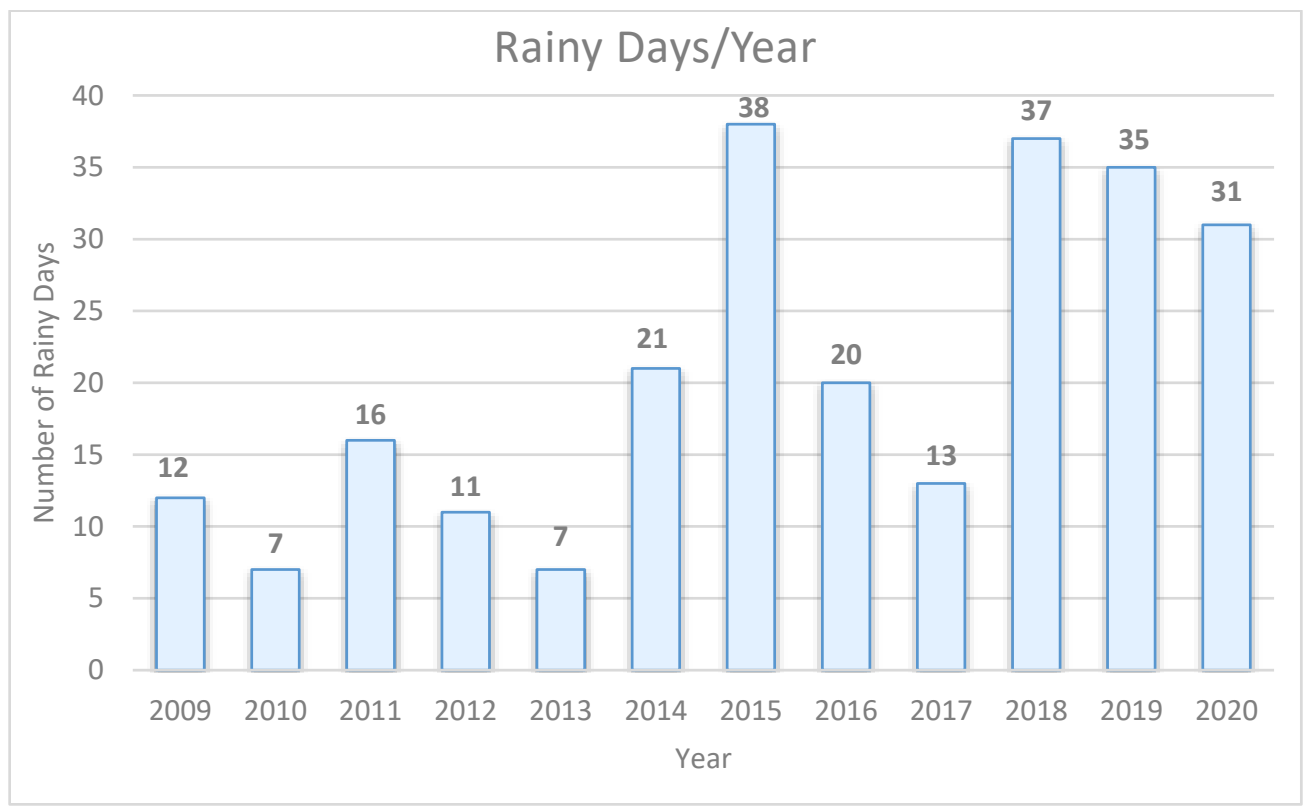

Fig. (2). Number of rainy days in the last 12 years. 


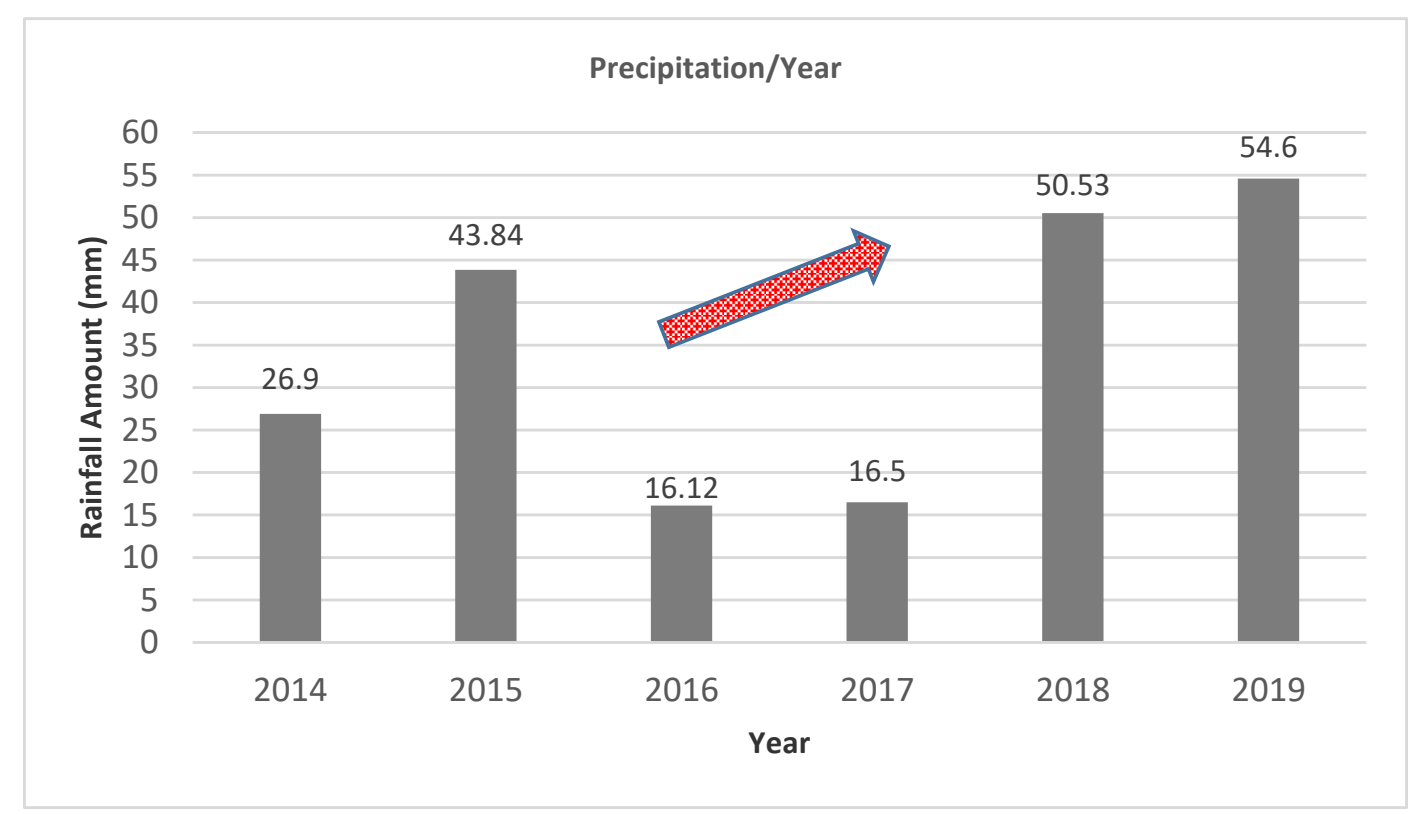

Fig. (3). Annual rainfall amount for last 5 years.

As far as the rainfall amount is concerned, the year 2018 and early 2019 have a high number compared to the previous years (Fig. 3). There is an increasing trend in the rainfall amount over the last six years, resulting from the climate change. However, the preceding 25 to 30 years' precipitation data will be required to establish a conclusion regarding a climate change scenario.
The last quarter of the year 2018 and early 2019 has a high number (Fig. 4). This unusuall high rainfall amount in a few rainy days reflects very intense precipitation. For example, in January 2019 , almost $40 \%$ of the annual rainfall occurred in just 4 days. This condition is followed by high surface and subsurface runoff.

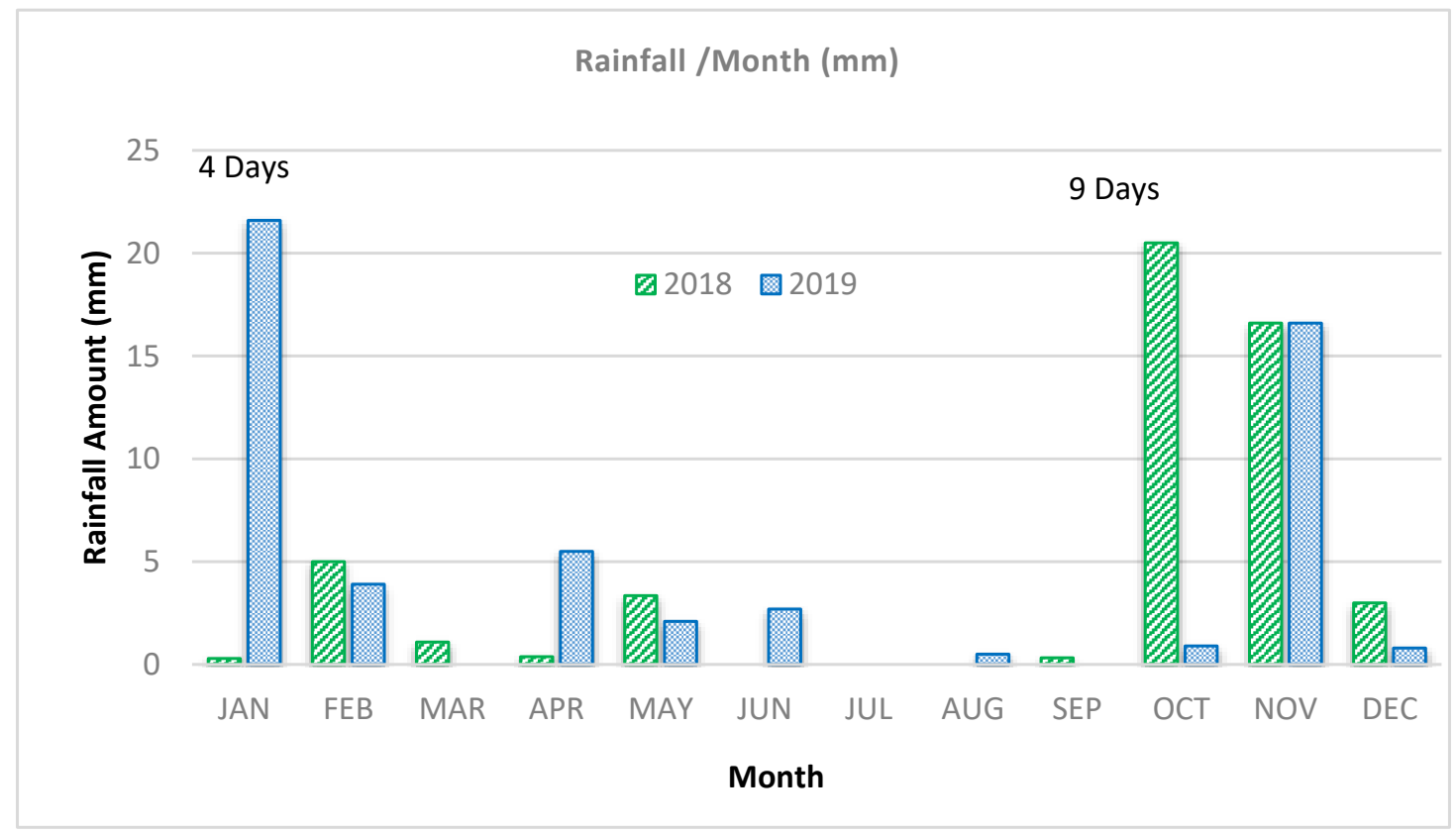

Fig. (4). Rainfall data for the previous 2-years. 
The remarkably high rainfall intensity, permeable sandy soil, and lack of ground vegetation will increase the ground infiltration of water, afterwhich the water can easily penetrate the soil layers, which usually remain dry. This soil strata near the surface are the most vulnerable. This situation will increase the soil moisture content and can then affect the performance of the foundation system. The isolated shallow foundations will be most affected due to their lower depth and dependence on relatively shallow layers of supporting soil.

\section{METHODOLOGY}

A 3-D FEM numerical analysis has been performed using COMSOL Multiphysics software to verify the moisture's effect on shallow foundations' behavior [21]. The model was carried out considering isolated, square, concrete foundations supported on a uniform sand layer. The foundation's behavior supporting the sand layer under different geotechnical and hydraulic conditions is the primary objective of this research. The numerical model was tested for the six cases designed based on sand density and saturation. Three relative densities of sand, namely, loose, medium, and dense, were tested against dry and saturated conditions. The relative density for the analyzed cases ranges from 30 to $80 \%$. The nomenclature of the numerical test cases is shown in Table 2. The first letter indicates the geotechnical condition, while the second letter represents the hydraulic condition. For example, 'Case-MS' means soil with Medium relative density has been tested under saturated conditions.

Table 2. Nomenclature of the considered cases in the FEM study.

\begin{tabular}{|c|c|c|}
\hline \multirow{2}{*}{ Relative Density Dr $(\%)$} & \multicolumn{2}{|c|}{ Moisture Condition } \\
\cline { 2 - 3 } & Dry & Saturated \\
\hline Loose $(\approx 30 \%)$ & Case-LD & Case-LS \\
\hline Medium $(\approx 50 \%)$ & Case-MD & Case-MS \\
\hline Dense $(\approx 80 \%)$ & Case-DD & Case-DS \\
\hline
\end{tabular}

The FEM results were then experimentally validated through simple 1-D element model tests. The laboratory tests were carried out by using standard consolidation equipment [22]. The experimental study was conducted on loose and medium relative densities.

\section{NUMERICAL ANALYSIS}

The 3-D FEM modeling and analysis for foundation and supporting soil layer have been done using the COMSOL Multiphysics program. The solid mechanic's module of the software has been adopted in this study. The dry soil and concrete were molded by using a linear elastic material node with soil plasticity and concrete sub-nodes, while the saturated conditions were molded by adopting the "poroelastic" node, also available in the solid mechanics module. The poroelastic interface associates a transient formulation of Darcy's law with a quasi-static formulation of solid mechanics. The link developed at the domain level, where the fluid pressure from the Darcy's Law interface acts as a load for the Solid Mechanics interface, which results in deformation. Equation 1 is the general equation for the Darcy law interface, which is given as:

$$
\rho_{f} S_{\alpha} \frac{\partial H}{\partial t}+\nabla \cdot \rho_{f}[-K \nabla H]=-\rho_{f} \alpha_{B} \frac{\partial \varepsilon_{v o l}}{\partial t}
$$

Where $\rho f$ is the density of the pore fluid, water in this case. ' $\mathbf{H}$ ' is the hydraulic head in length units, $\mathbf{K}$ is the coefficient of permeability, $\boldsymbol{\varepsilon}_{\mathrm{vol}}$ is the material's volumetric strain, and $\boldsymbol{\alpha}_{\mathbf{B}}$ is Biot-Willis Coefficient. The value of the Biot-Willis coefficient is assumed to be 1.0 for soft poroelastic material such as soil. $\mathbf{S}_{\boldsymbol{\alpha}}$ is the poroelastic storage coefficient. The volumetric extension will give a negative sign to the right-hand side of the equation. The density of water is taken as 1000 $\mathrm{kg} / \mathrm{m}^{3}$.

The mechanical behavior of the poroelastic material is governed by:

$$
-\nabla \cdot \sigma=\rho g
$$

Where ' $\rho$ ' is the overall density of the porous material, $\sigma$ is the stress tensor, and $g$ is the gravitational acceleration. The stress tensor's nomenclature $\sigma$ defined in equation 2 is given in equation 3 , whereas the respective strain tensor $\varepsilon$ is defined in equation 4 .

$$
\begin{gathered}
\sigma=\left[\begin{array}{lll}
\sigma_{x x} & \sigma_{x y} & \sigma_{x z} \\
\sigma_{y x} & \sigma_{y y} & \sigma_{y z} \\
\sigma_{z x} & \sigma_{z y} & \sigma_{z z}
\end{array}\right] \\
\varepsilon=\left[\begin{array}{lll}
\varepsilon_{x x} & \varepsilon_{x y} & \varepsilon_{x z} \\
\varepsilon_{y x} & \varepsilon_{y y} & \varepsilon_{y z} \\
\varepsilon_{z x} & \varepsilon_{z y} & \varepsilon_{z z}
\end{array}\right]
\end{gathered}
$$

In equations 3 and $4, \boldsymbol{\sigma}_{\mathrm{xx}}, \boldsymbol{\sigma}_{\mathrm{yy}}$, and $\boldsymbol{\sigma}_{\mathrm{zz}}$ are normal stresses, and $\varepsilon_{\mathrm{xx}}, \boldsymbol{\varepsilon}_{\mathrm{yy}}$, and $\boldsymbol{\varepsilon}_{\mathrm{zz}}$ are normal strains.

\subsection{Geotechnical Conditions}

Al Madinah Al Munawwarah is a desert oasis surrounded by mountains and rocky areas. The main city is overlayed on sandy formations. The top 3 to $10-\mathrm{m}$ deep layers mainly consist of sand, with relative density ranging from loose to very dense. The soil considered in this study has been taken from an open pit located in the eastern part of the city. The index properties and relative density of the soil have been determined at the laboratory as per ASTM standards [23]. Grain size distribution curve i.e., the relative proportions of different particle sizes for Al-Madinah soil is shown in Fig. (5). The uniformity coefficient of the soil is 3.64 as per the Unified Soil Classification System (USCS); Type of soil is "S.P.," which is poorly Graded sand [24]. The soil is nonplastic in nature. The key index properties of the soil used to estimate required parameters in the numerical modeling are tabulated in Table 3.

This soil has slightly lower specific gravity than usual. This is probably due to the absence of heavy minerals in the sand. 


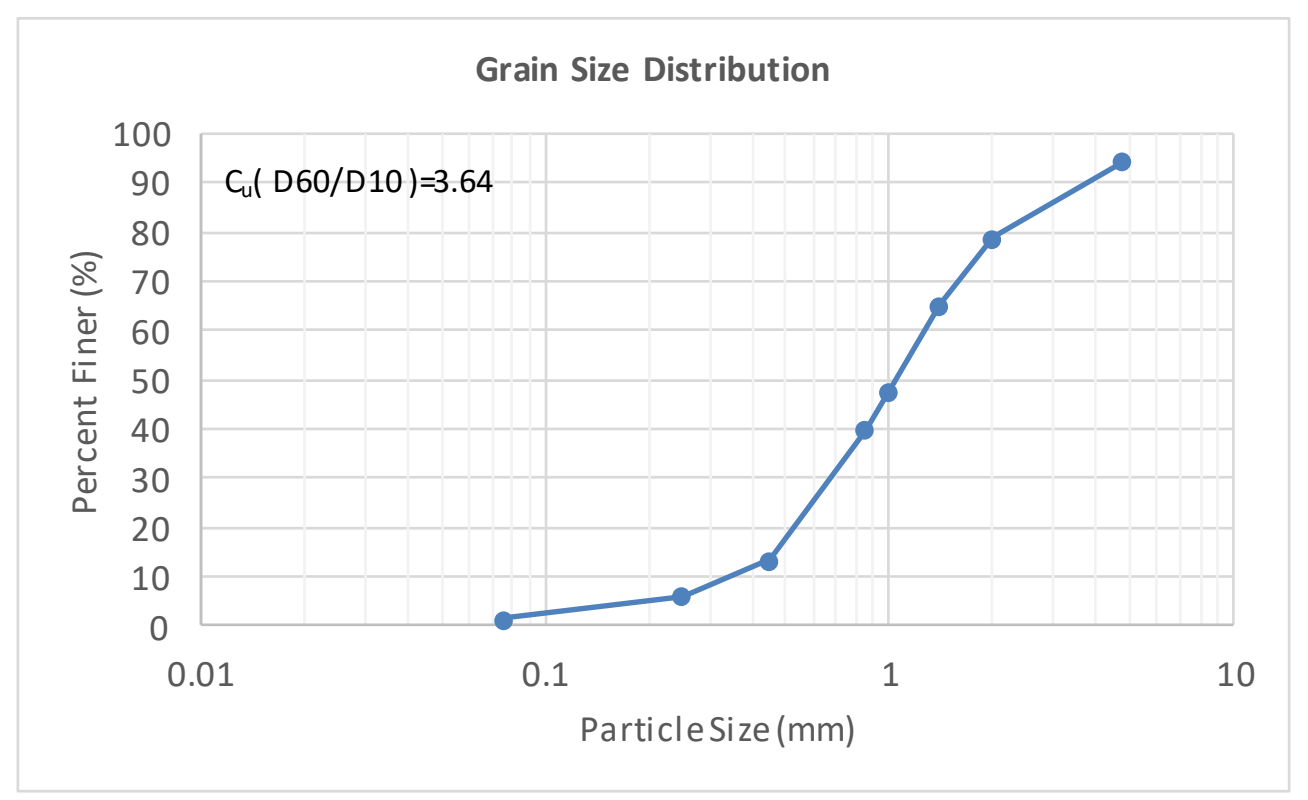

Fig. (5). Grain size distribution curve for Madinah soil.

Table 3. Index properties of Madinah soil.

\begin{tabular}{|c|c|c|}
\hline Sr. No & Parameter & Value \\
\hline $\mathbf{1}$ & Uniformity Coefficient $(\mathrm{Cu})$ & 3.64 \\
\hline $\mathbf{2}$ & Plasticity Index (P.I.) & Non-Plastic \\
\hline $\mathbf{3}$ & Maximum Dry Density $\rho_{\mathrm{d}}$ max. (Unit Weight $\gamma_{\mathrm{d}}$ max.) & $1630 \mathrm{~kg} / \mathrm{m}^{3}\left(16.0 \mathrm{kN} / \mathrm{m}^{3}\right)$ \\
\hline $\mathbf{4}$ & Minimum Dry Density $\rho_{\mathrm{d}}$ min. (Unit Weight $\gamma_{\mathrm{d}}$ min.) & $1406 \mathrm{~kg} / \mathrm{m}^{3}\left(13.8 \mathrm{kN} / \mathrm{m}^{3}\right)$ \\
\hline $\mathbf{5}$ & Unified Soil Classification & S.P.' Poorly graded Sand \\
\hline $\mathbf{7}$ & Specific Gravity (Gs) & 2.52 \\
\hline
\end{tabular}

\subsection{Model Data}

The general model geometry is shown in Fig. (6a). The 20$\mathrm{m} \times 20-\mathrm{m}$ soil section, consisting of sand, is considered an area of interest. The isolated reinforced concrete foundation size was taken as $2 \mathrm{~m}$ by $2 \mathrm{~m}$. The $2-\mathrm{m}$ wide foundation has an influence zone of around 4-m depth. The foundation's influence zone, i.e., the thickness of the sand layer, is assumed based on Boussinesq's isobars for square and continuous footing [25]. The thickness of the sand layer is assumed as $5-\mathrm{m}$ and the concrete foundations are $0.5-\mathrm{m}$ thick. The generated mesh for FEM analysis is shown in Fig. (6b). The model sides, i.e., a surface parallel to $\mathrm{x}-\mathrm{z}$ and $\mathrm{y}-\mathrm{z}$ planes, are considered roller supports. The model is assumed to be resting on stiff impervious bedrock and hence, considered to be fixed at the bottom. The top surface is kept free. The effect of backfill soil is not considered for concrete foundations. As a worst-case scenario, the drainage was only allowed to form at the top of the model.

Table 4. Adopted/calculated parameters for the numerical models.

\begin{tabular}{|c|c|c|c|c|}
\hline Description \& Standard Symbol & \multirow{2}{*}{ Unit } & \multicolumn{3}{|c|}{ Soil Relative Density Dr. (\%) } \\
\cline { 3 - 6 } & & $\begin{array}{c}\text { Loose } \\
\mathbf{3 0 \%}\end{array}$ & $\begin{array}{c}\text { Medium } \\
\mathbf{5 0 \%}\end{array}$ & $\begin{array}{c}\text { Dense } \\
\mathbf{8 0} \%\end{array}$ \\
\hline Soil Bulk Modulus $\left(\mathrm{K}_{\text {soil }}\right)$ & $\mathrm{MPa}$ & 12.5 & 33.33 & 58.33 \\
\hline Soil Dry Density $\left(\rho_{\mathrm{d}}\right)$ & $\mathrm{kg} / \mathrm{m}^{3}$ & 1470 & 1510 & 1580 \\
\hline Void ratio $(\mathrm{e})$ & $\mathrm{ratio}$ & 0.7187 & 0.6694 & 0.5954 \\
\hline Porosity $(\mathrm{n})$ & $\mathrm{ratio}$ & 0.4170 & 0.400 & 0.3730 \\
\hline Soil Friction Angle $(\phi)$ & $\mathrm{deg}$ & 30.4 & 34.0 & 39.4 \\
\hline Soil Dilation Angle $(\psi)$ & $\mathrm{deg}$ & 0.4 & \multicolumn{3}{|c|}{4} & 9.4 \\
\hline Cohesion $(\mathrm{C})$ & $\mathrm{kPa}$ & & \multicolumn{2}{c}{0} \\
\hline
\end{tabular}




\begin{tabular}{|c|c|c|c|c|}
\hline \multirow[t]{2}{*}{ Description \& Standard Symbol } & \multirow[t]{2}{*}{ Unit } & \multicolumn{3}{|c|}{ Soil Relative Density Dr. (\%) } \\
\hline & & $\begin{array}{c}\text { Loose } \\
30 \%\end{array}$ & $\begin{array}{c}\text { Medium } \\
\mathbf{5 0 \%}\end{array}$ & $\begin{array}{c}\text { Dense } \\
\mathbf{8 0 \%}\end{array}$ \\
\hline Reinforced Concrete Density ( $\left.\rho_{\text {concrete }}\right)$ & $\mathrm{kg} / \mathrm{m}^{3}$ & \multicolumn{3}{|c|}{2500} \\
\hline The density of water $\left(\rho_{f}\right)$ & $\mathrm{kg} / \mathrm{m}^{3}$ & \multicolumn{3}{|c|}{1000} \\
\hline Soil Elasticity Modulus $\left(\mathrm{E}_{\text {soil }}\right)$ & $\mathrm{MPa}$ & 15 & 40 & 70 \\
\hline Concrete Elasticity Modulus ( $\left.\mathrm{E}_{\text {concrete }}\right)$ & $\mathrm{Pa}$ & \multicolumn{3}{|c|}{$1 \times 10^{11}$} \\
\hline Poisons ratio Soil $\left(v_{\text {soil }}\right)$ & ratio & \multicolumn{3}{|c|}{0.30} \\
\hline Poisons ratio Concrete $\left(v_{\text {concrete }}\right)$ & ratio & \multicolumn{3}{|c|}{0.35} \\
\hline Soil absolute permeability $(\mathrm{K})$ & $\mathrm{m} 2$ & \multicolumn{3}{|c|}{$1 \times 10^{-11}$} \\
\hline Soil Shear Modulus $(\mathrm{G})$ & {$[\mathrm{MPa}]$} & 5.76 & 15.38 & 27 \\
\hline Spring Constant Modulus of subgrade reaction (k) & $\mathrm{kN} / \mathrm{m}^{2} / \mathrm{m}$ & 15000 & 70000 & 100000 \\
\hline Applied Stress (load) (q) & $\mathrm{kN} / \mathrm{m}^{2}$ & \multicolumn{3}{|c|}{200} \\
\hline
\end{tabular}

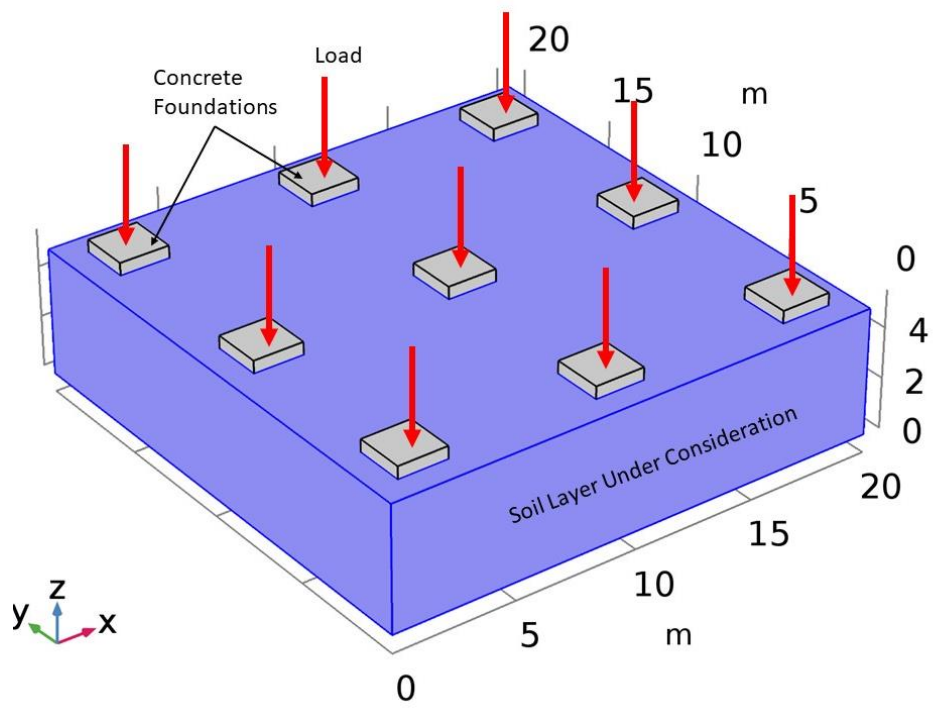

(a)

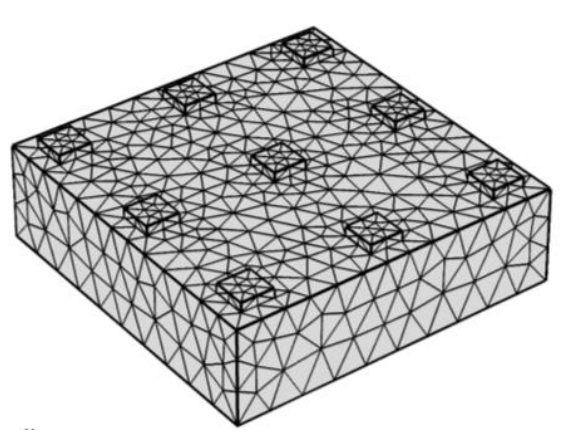

(b)

Fig. (6). Geometry of the foundation system (a) Foundation system model with dimensions and (b) Model mesh for FEM analysis.

A load of $200 \mathrm{kN} / \mathrm{m}^{2}$ was applied as a uniformly distributed load on each isolated footing. It is assumed to be simulated for 4 story building having a total factored load of $200 \mathrm{kN} / \mathrm{m}^{2}$ with a tributary area of $400 \mathrm{~m}^{2}$, as mentioned in Fig. (6a). Based on the three selected relative densities, the geotechnical parameters were estimated from the classical soil mechanics correlations; the standard values of concrete parameters have been selected. The details of the parameters adopted in this study are shown in Table 4.

\section{RESULTS}

The FEM numerical analysis was done by the built-in iterative solver using the Generalized Minimal Residual Method (GMRES) [26]. The error tolerance was kept to $10^{-5}$. The tolerance level was achieved with few iterations, for example, in Case L.D., the error tolerance of $10^{-5}$ was achieved in just 12 iterations. The examples of FEM results for the six considered cases are discussed in this section. The displacement and pressure plot for the Case L.D. are shown in Fig. (7). This case involves the numerical testing of dry sand with loose relative density, i.e., around 30\%. Fig. (7a) shows the total displacement plot for the foundation system. The total displacement " $U$ " is defined in equation (5) as follows:

$$
U=\sqrt{u_{x}^{2}+u_{y}^{2}+u_{z}^{2}}
$$

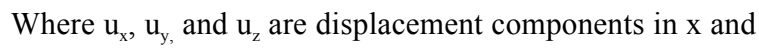
$\mathrm{z}$ directions. The maximum displacement of $17-\mathrm{mm}$ was observed at the corner foundations, however, the difference in displacement between corner and middle foundations is marginal. The influence zone of the foundations and deformed shape can be seen in the figure below. The initial assumption of a 5-m thick soil layer was proved to be very effective, and no deformation was observed at that depth. Since the resultant displacement is in the " $z$ " direction, it can be directly related to the foundation settlement. 
Volume: Total displacement (mm)

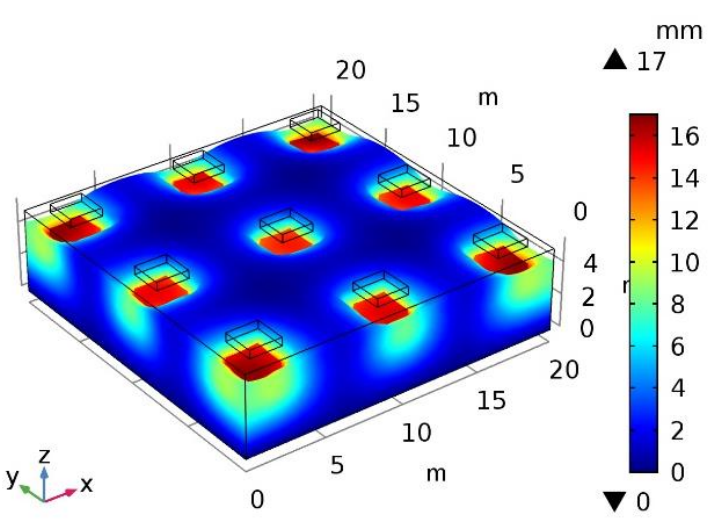

(a)

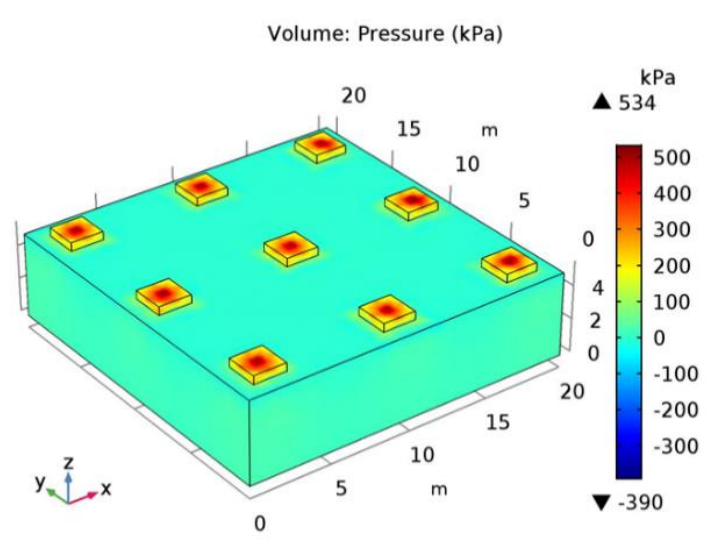

(b)

Fig. (7). Displacement and stress distribution for Case L.D. (Loose Dry Soil), (a) Total displacement and deformed shape and (b) Overall pressure distribution.

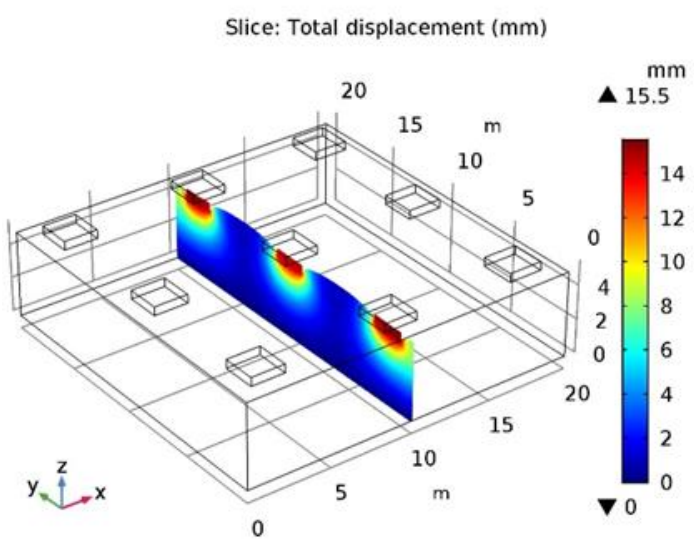

(a)
Slice: Total displacement $(\mathrm{mm})$

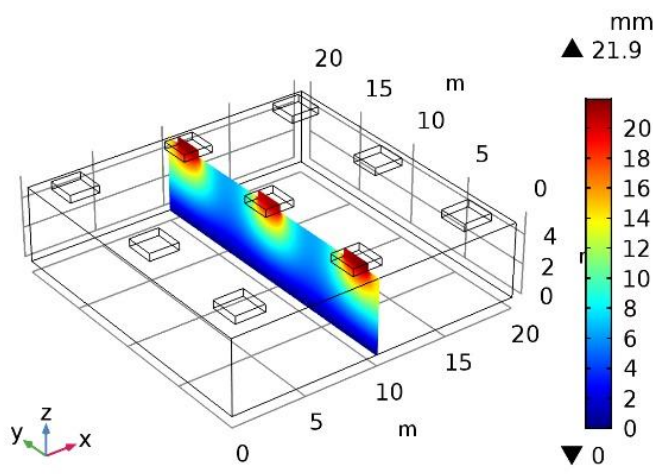

(b)

Fig. (8). Comparison of sectional displacement for dry and saturated conditions (a) Sectional displacement case L.D. (Loose Dry Soil) and (b) Sectional displacement case L.S. (Loose Saturated Soil).

The pressure plot for the loose dry case (Case L.D.) is shown in Fig. (7b). The pressure "P" presented in the figure is defined by Equation 6:

$$
P=\frac{\sigma_{x x}+\sigma_{y y}+\sigma_{z z}}{3}
$$

In this case, $\mathrm{P}$ is the pressure, $\sigma_{\mathrm{xx}}, \sigma_{\mathrm{yy}}$, and $\sigma_{\mathrm{zz}}$ are normal stresses. In the case of principal stresses, this pressure is similar to the mean principal stress, used to indicate the stress path in the triaxial tests. In Fig. (7b), the maximum pressure value is $534 \mathrm{kPa}$, located at the centre of the concrete foundation. Due to being a strong material, reinforced concrete has absorbed most of the stresses. The value of stress in the considered loose sand layer ranges from $0-150 \mathrm{kPa}$.

The total displacement for loose sand under dry and wet conditions has been compared in Fig. (8). The slice surface plot parallels the $y-z$ plane at an intercept of $10-\mathrm{m}$ from the origin (i.e., at the middle of the foundation section). Case L.D. and L.S. are respectively shown in Figs. (8a and $\mathbf{8 b}$ ).

Under the same geotechnical and loading conditions, the maximum sectional displacement for the dry case was 15.5 $\mathrm{mm}$, while it increases to $21.9 \mathrm{~mm}$ for the saturated case. The displacement influence zone for the saturated case is deeper and widely spread than the dry case, however, the stress distribution pattern is similar. For both cases, no settlement was observed at the bottom of the sand layer.

The stress-strain behavior of the foundation system is expressed by plotting $1^{\text {st }}$ principal invariant of stresses " $\mathrm{I}_{1}$ "and the volumetric strain " $\varepsilon_{\text {vol }}$ " (Fig. 9). Case MS (Sand with medium relative density under saturated condition) has been 
selected for Fig. (9). The $1^{\text {st }}$ invariant of the stress tensor is given by equation 7 :

$$
I_{1}=\sigma_{x x}+\sigma_{y y}+\sigma_{z z}
$$

The respective volumetric strain " $\varepsilon_{\mathrm{vol}}$ " is defined by equation 8:

$$
\varepsilon_{v o l}=\varepsilon_{x x}+\varepsilon_{y y}+\varepsilon_{z z}
$$

The contour plot for the stress invariant is shown in Fig. (9a); similar to the previous cases, most of the R.C. foundations took most of the stresses. The blue patches at the bottom of the isolated foundation indicate the presence of tensile pressure. The volumetric strain distribution is presented in Fig. (9b); although the overall strain magnitude is low, the

Contour: First principal invariant of stress (MPa)

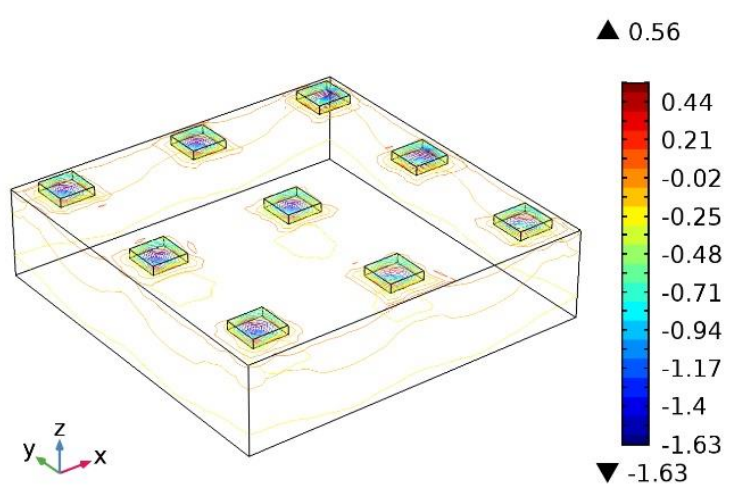

(a) strain contours are concentrated in the soil along the foundation. The maximum strain is located at the contact point of the foundation and the soil.

\subsection{Experimental Validation}

1-D element model tests were conducted to observe the settlement behavior of sand experimentally. These tests were performed at the Soil Mechanics Laboratory of the faculty of engineering, Islamic University of Madinah. The experiments were performed on a standard semi-automatic consolidation machine manufactured by ELE international. The soil sample was prepared by using dry sand; the sample diameter was 50 $\mathrm{mm}$ while its thickness was $20-\mathrm{mm}$. The soil sample after the completion of the tests is shown in Fig. (10). It should be noted that the sand gets disturbed during the extraction process.

Contour: Volumetric strain (1)

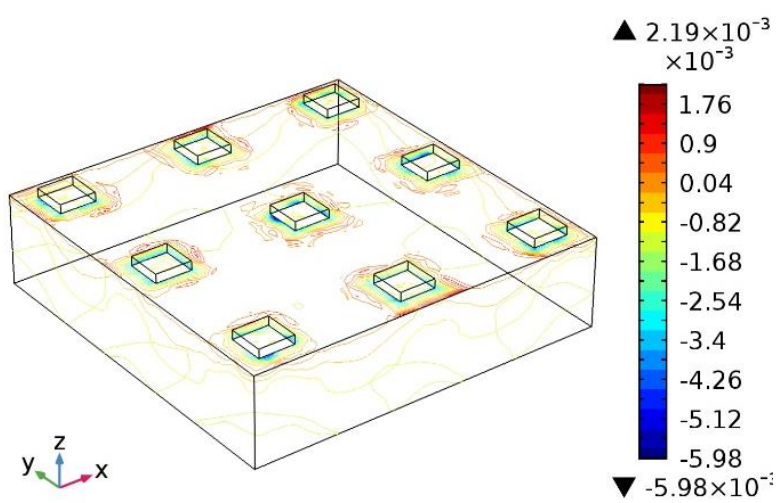

(b)

Fig. (9). Stress-strain contours for case M.S. (Medium-Saturated Soil) (a) 1st invariant of principal stresses case MS (Medium-Saturated Soil) and (b) Volumetric strain case MS (Medium-Saturated Soil)

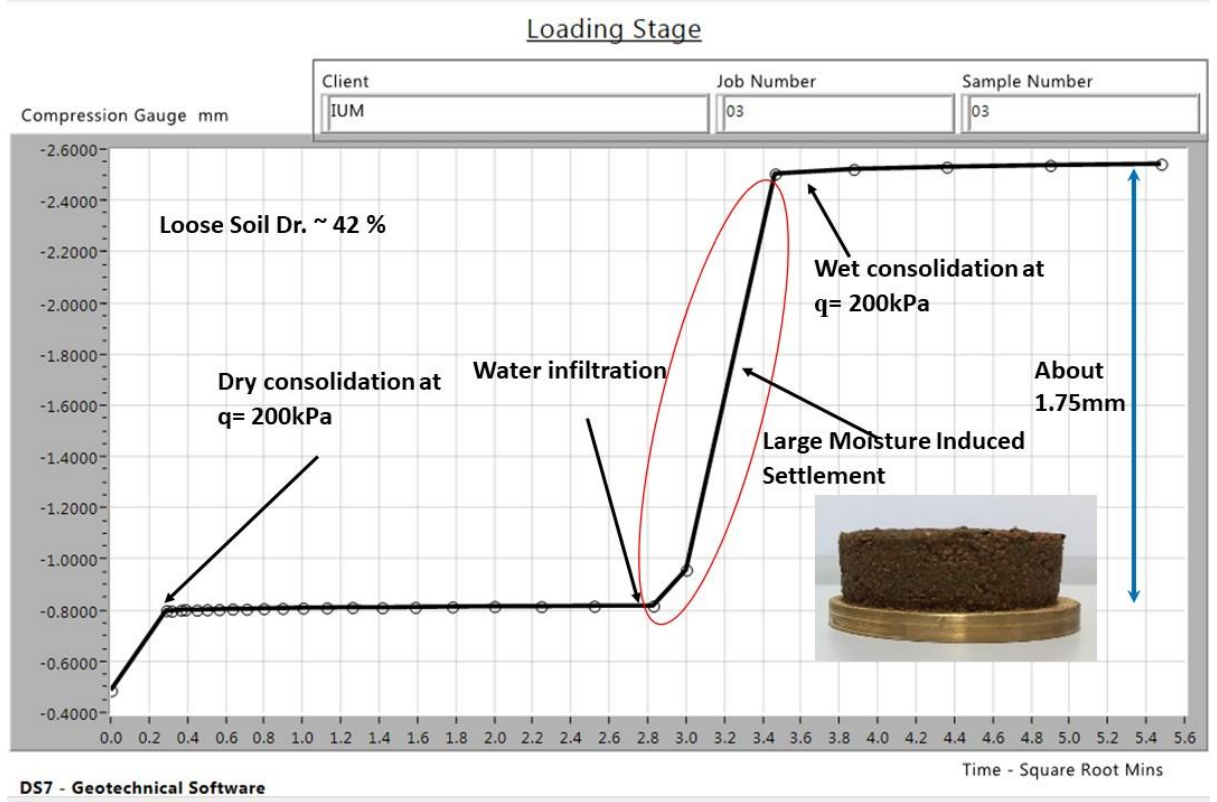

Fig. (10). 1-D infiltration test at $200 \mathrm{kPa}$ stress for loose soil. 


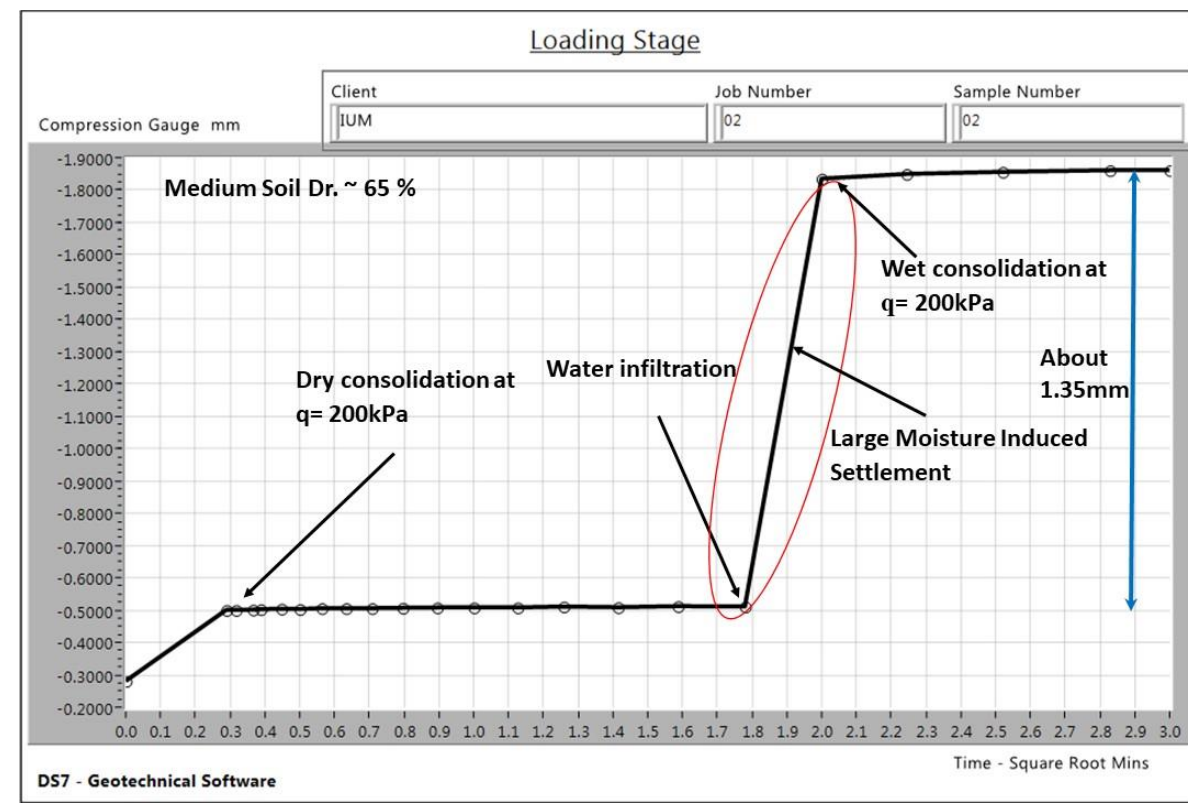

Fig. (11). 1-D infiltration test at $200 \mathrm{kPa}$ stress for Medium soil.

Two tests were performed, one for loose soil and the other on soil with medium density. In both cases, the soil was initially consolidated at $100-\mathrm{kPa}$, and after the completion of the $1^{\text {st }}$ step, the design load of $200-\mathrm{kPa}$ was applied. After the consolidation was completed at $200-\mathrm{kPa}$, the samples were flooded with water to present the rainfall event. The water has introduced large settlements in both the cases. The experiment results for loose and medium cases are respectively presented in Figs. (10 and 11). The water infiltration introduces about $1.75 \mathrm{~mm}$ settlement in the loose soil and about $1.35 \mathrm{~mm}$ settlement in the medium soil. The loose soil has slightly more settlement than the medium one; this reflects a good comparison with numerical analysis results. The abrupt settlement due to water infiltration is an indication that some of the Madinah soils have the potential of collapsibility. An analytical framework can be applied to the soil for further investigation of the collapsibility.

\section{DISCUSSION}

The total displacement results of all six numerical cases are shown in Fig. (12). The peak displacement in the foundation system is presented in the figure concerning their relative density and saturation condition. The presence of water increases the displacement in all three relative densities. In the case of loose soil, the saturated soil settlement increased from $17 \mathrm{~mm}$ to $23.5 \mathrm{~mm}$; it increased from $6.39 \mathrm{~mm}$ to $8.87 \mathrm{~mm}$ for medium soil and from $3.6 \mathrm{~mm}$ to 5.11 when dense soil was considered. The increase in displacement due to moisture ranges from 38 to $40 \%$. It should be noted that the displacement under $200 \mathrm{kPa}$ stress remained within a tolerable limit of $25 \mathrm{~mm}$ for all the cases. However, the maximum displacement in loose saturated soil is about to approach the threshold level.

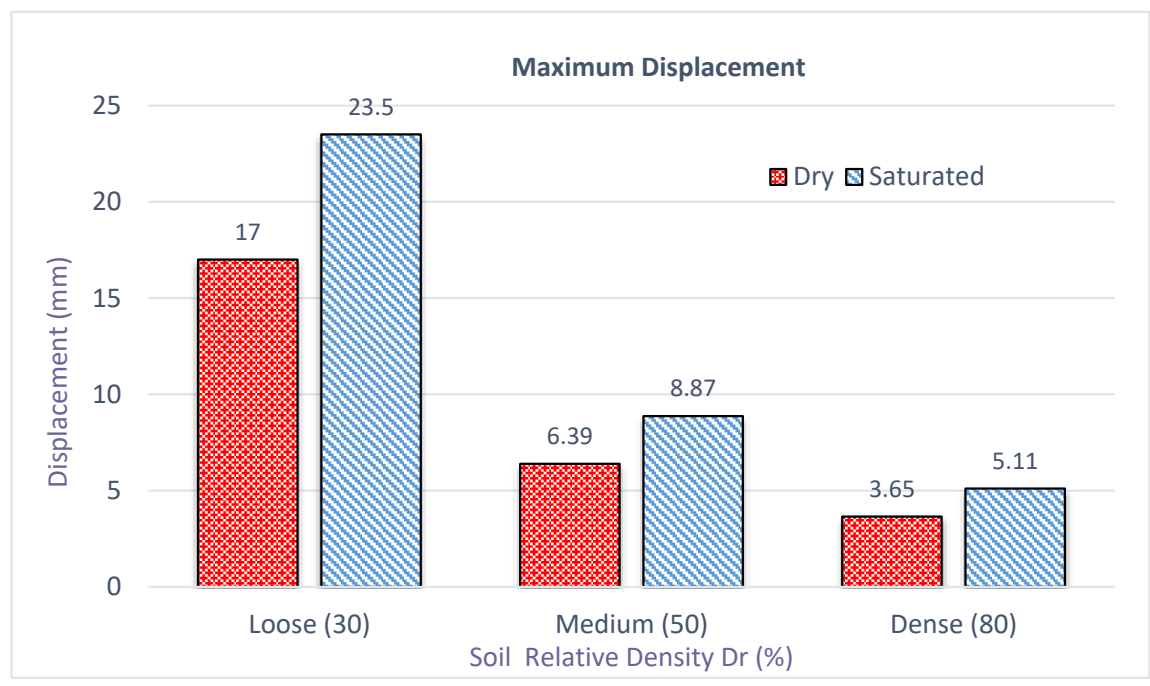

Fig. (12). Summary of maximum settlement in foundation systems. 


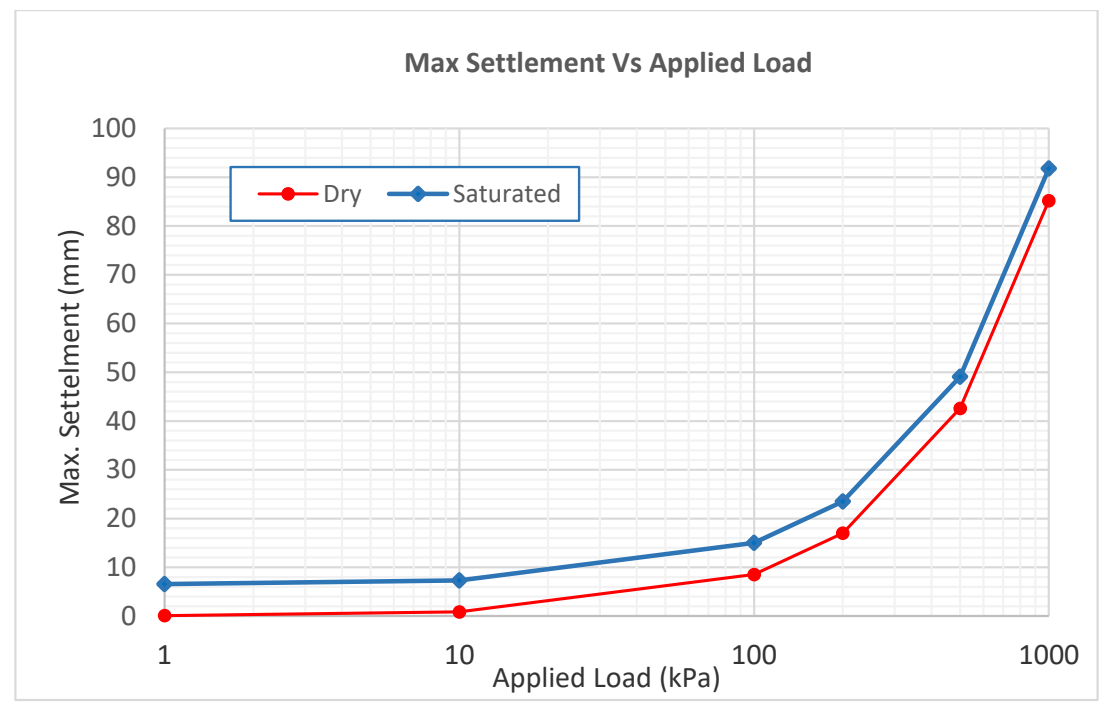

Fig. (13). Settlement for loose soil cases at different loadings.

In buildings, the foundation's subsidence depend on the applied loading, the relative density of the sand, soil moisture, and downward seepage forces (during infiltration). Under considered circumstances, the low infiltration rate and initial soil suction limit the seepage forces as compared to the mechanical loading. The increase in the foundation settlement is mostly due to the lower soil relative density and increase in the moisture content. The dry sand of the foundation influence zone donot become permeability saturated soil after the rainfall event. The rainwater infiltrates further below and joins the much deeper aquifer. However, the foundation supporting strata remains partially saturated for a longer duration (depending on the soil suction value). Studying the foundation settlement under wetting and drying cycles will be interesting phenomena; nevertheless, under current geological conditions, the existing sandy soil with little or no fines rarely exhibits shrink-swell behavior, and the geotechnical problem is mostly associated with the additional compaction of soil strata due to the lubrication of soil grains under moist conditions. This can be seen from Fig. (12), where dense soil is least affected by the moisture variation.

The 1-D experimental tests discussed in section 5.1 confirm the possibility of moisture-induced settlement in preloaded foundations. The experiments were performed under very different geometric conditions, and experimental results qualitatively demonstrate the settlement of pre-loaded foundations under changing moisture conditions.

To further explain moisture's effect on shallow foundations' performance, the most vulnerable loose soil cases (Loose Dry and Loose Saturated) are numerically verified for various loading conditions. The result of these trials is summarized in Fig. (13).

Both the cases are tested against six different loading levels. The maximum displacement from each test case is plotted against the applied load on a semi-logarithmic chart. It is clear from the figure that the water-based displacement is more prominent in lightly loaded structures. At around $250 \mathrm{kPa}$ stress, the displacement in the saturated soil crosses the threshold level of $25 \mathrm{~mm}$. With the increase in building load, the difference in peak displacement between wet and dry soil becomes marginalized.

\section{CONCLUSION}

The City of Al-Madinah, Al-Munawara has a mostly dry climate with infrequent rainfall patterns; however, intensive precipitation events have been recorded in recent times, such as in January 2019. There is an increasing trend in the annual rainfall amount, which may be an indication of the climate change in the region. The city buildings are mostly resting on sandy soil, which has high permeability and moisture, the penetration of which, up to the influence zone of shallow foundations, is obvious in cases of an intense rainstorm.

The FEM-based numerical analysis conducted on isolated foundations, supported by local soil, with varying relative density and degree of saturation, revealed an enhanced foundation settlement. However, the magnitude of the settlement is more prominent in the loose soil. The 1-D experimental test results verify the findings of the FEM analysis. Differential loads and non-uniform soils can pose a high risk to the stability of structures supported by isolated foundations. The observed settlement in medium and dense sand is limited, and proper compaction and detailed geotechnical investigations can easily control moisture-induced settlements.

To achieve the sustainability of infrastructure at harem al Madinah, under possible changing climatic conditions. Soil properties, such as permeability and the overall extent of moisture penetration, must be studied in more detail under saturated conditions. The stricter compaction control will help reduce the risk associated with rainfall-induced settlements. It is highly recommended for future construction projects to study the water flow patterns, followed by precipitation, and incorporate its interception and disposal methods in the design. The development and propagation of cracks in buildings after an intense rainfall event should be monitored carefully for the damage assessment and future design recommendations. In this 
context, community response must be sought and appreciated. Smart early warning systems coupled with soil moisture sensors can also be installed at critical locations for vital infrastructure.

\section{LIST OF ABBREVIATIONS}

$$
\begin{aligned}
& \mathbf{u}_{\mathbf{x}}, \mathbf{u}_{\mathbf{y}} \text {, and } \mathbf{u}_{\mathrm{z}} \quad=\text { Displacement Components in } \mathrm{x} \text { and } \mathrm{z} \text { Directions } \\
& \boldsymbol{\sigma}_{\mathrm{xx}}, \boldsymbol{\sigma}_{\mathrm{yy}}, \text { and } \boldsymbol{\sigma}_{\mathrm{zz}}=\text { Normal Stresses } \\
& \boldsymbol{\varepsilon}_{\mathrm{xx}}, \boldsymbol{\varepsilon}_{\mathrm{yy}} \text {, and } \boldsymbol{\varepsilon}_{\mathrm{zz}}=\text { Normal Strains } \\
& \text { f } \quad=\text { Density of the Pore Fluid } \\
& \text { H = Hydraulic Head in Length Units } \\
& \text { K }=\text { Coefficient of Permeability } \\
& \boldsymbol{\varepsilon}_{\mathrm{vol}} \quad=\text { Volumetric Strain of the Material } \\
& \boldsymbol{\alpha}_{\mathrm{B}} \quad=\text { Biot-Willis Coefficient } \\
& \mathbf{S}_{\boldsymbol{a}} \quad=\text { Poroelastic Storage Coefficient } \\
& \mathbf{U} \quad=\text { Total Displacement } \\
& \text { p } \quad=\text { Overall Density of the Porous Material } \\
& \boldsymbol{\sigma} \quad=\text { Stress Tensor } \\
& \text { g = Gravitational Acceleration } \\
& \boldsymbol{\varepsilon}=\text { Strain Tensor }
\end{aligned}
$$

\section{CONSENT FOR PUBLICATION}

Not applicable.

\section{AVAILABILITY OF DATA AND MATERIALS}

Not applicable.

\section{FUNDING}

This research was funded by the Deanship of Scientific Research, Islamic University of Madinah, Kingdom of Saudi Arabia through research project number 86/40.

\section{CONFLICT OF INTEREST}

The author declares no conflict of interest, financial or otherwise.

\section{ACKNOWLEDGEMENTS}

The administrative and technical support provided by the Faculty of Engineering, Islamic University of Madinah, is acknowledged.

\section{REFERENCES}

[1] G.S. Budi, "Settlement of residential houses supported by piled foundation embedded in expansive soil", Procedia Eng., vol. 171, pp. 454-460, 2017.

[http://dx.doi.org/10.1016/j.proeng.2017.01.356]

[2] M.A. Shahriar, N. Sivakugan, A. Urquhart, M. Tapiolas, and B.M. Das, "A study on the influence of ground water level on foundation settlement in cohesionless soil", Proceedings of the $18^{\text {th }}$ International Conference on Soil Mechanics and Geotechnical Engineering: Challenges and Innovations in Geotechnics, 2013 ICSMGE, 2013.

[3] J. Valença, L.M.S. Gonçalves, and E. Júlio, "Damage assessment on concrete surfaces using multi-spectral image analysis", Constr. Build. Mater., 2013. [http://dx.doi.org/10.1016/j.conbuildmat.2012.11.061]

[4] J.B. Burland, and C.P. Wroth, "Settlement of buildings and associated damage", Proceedings of the Conference of the British Geotechnical Society, 1974.

[5] R.J. Mair, R.N. Taylor, and J.B. Burland, "Prediction of ground movements and assessment of risk of building damage due to bored tunnelling", Proceedings of the Geotechnical Aspects of Underground Construction in Soft Ground, 1996.

[6] M. Preene, "Assessment of settlements caused by groundwater control", Proceedings of the Institution of Civil Engineers: Geotechnical Engineering, 2000.

[http://dx.doi.org/10.1680/geng.2000.143.4.177]

[7] T. Vo, and A.R. Russell, "Bearing capacity of strip footings on unsaturated soils by the slip line theory", Comput. Geotech., vol. 74, pp. 122-131, 2016.

[http://dx.doi.org/10.1016/j.compgeo.2015.12.016]

[8] S. Capdevila, G. Roqueta, M. Guardiola, L. Jofre, J. Romeu, and J.C. Bolomey, "Water infiltration detection in civil engineering structures using RFID", Proceedings of the Proceedings of 6th European Conference on Antennas and Propagation., 2012 EuCAP, 2012. [http://dx.doi.org/10.1109/EuCAP.2012.6206147]

[9] G.A. Siemens, and J.A. Blatz, "Numerical modelling of shallow foundations on swelling clay soil using the swelling equilibrium limit", Proceedings of the Unsaturated Soils: Advances in Geo-Engineering Proceedings of the 1st European Conference on Unsaturated Soils, 2008 E-UNSAT, 2008

[10] A.E. Alluqmani, Q.U. Farooq, and O. Harireche, "A semi-analytical framework for one-dimensional collapse analysis of partly saturated soils", Innovative Infrastructure Solutions, vol. 5, p. 5, 2020. [http://dx.doi.org/10.1007/s41062-019-0255-7]

[11] R. Nova, and L. Montrasio, "Settlements of shallow foundations on sand", Geotechnique, 1991.

[http://dx.doi.org/10.1680/geot.1991.41.2.243]

[12] R.S. Pugh, "Some observations on the influence of recent climate change on the subsidence of shallow foundations", Proceedings of the Institution of Civil Engineers: Geotechnical Engineering, 2002. [http://dx.doi.org/10.1680/geng.155.1.23.40623]

[13] Y. Tang, H.A. Taiebat, and A.R. Russell, "Bearing capacity of shallow foundations in unsaturated soil considering hydraulic hysteresis and three drainage conditions", Int. J. Geomech., 2017.

[http://dx.doi.org/10.1061/(ASCE)GM.1943-5622.0000845]

[14] Q.U. Farooq, and B. Ahmed, "Shaath the appraisal of hybrid foundations on loose granular soil of western saudi arabia", Proceedings of Engineering and Technology Innovation, . [http://dx.doi.org/10.46604/peti.2020.5515]

[15] F. Stracke, J.G. Jung, E.P. Korf, and N.C. Consoli, The influence of moisture content on tensile and compressive strength of artificially cemented sand., Soils and Rocks, 2012.

[16] S. Assouline, "Infiltration into soils: Conceptual approaches and solutions", Water Resour. Res., 2013.

[http://dx.doi.org/10.1002/wrcr.20155]

[17] H. Liu, T.W. Lei, J. Zhao, C.P. Yuan, Y.T. Fan, and L.Q. Qu, "Effects of rainfall intensity and antecedent soil water content on soil infiltrability under rainfall conditions using the run off-on-out method", J. Hydrol. (Amst.), 2011.

[http://dx.doi.org/10.1016/j.jhydrol.2010.10.028]

[18] M. Bob, N. Rahman, A. Elamin, and S. Taher, "Rising groundwater levels problem in urban areas: A case study from the central area of madinah city, saudi arabia", Arab. J. Sci. Eng., 2016. [http://dx.doi.org/10.1007/s13369-015-1976-3]

[19] S.A. Gutub, "A case study of al- madinah 's water resources and reclaimed wastewater reuse perspective", International Journal of Cvivil and Envirmental Engineering IJCEE-IJENS, 2013.

[20] World Weather Online, World Weather Online, 2012.

[21] COMSOL Inc, COMSOL Multiphysics Reference Manual (version 5.3a)., Comsol, 2018.

[22] ASTM D 2435/ D2435M -11, "Standard test methods for onedimensional consolidation properties of soils using incremental loading",

[http://dx.doi.org/10.1520/D1883-07E02.dry]

[23] "ASTM D422 standard test method for particle-size analysis of soils", Astm, 2018.

[24] "Astm; international, A. standard practice for classification of soils for engineering purposes (unified soil classification system)", ASTM Standard Guide, 2006.

[http://dx.doi.org/10.1520/D2487-11.]

[25] Cernica John N, "Geotechnical engineering: Foundation design", 
Choice Reviews Online, 1995.

[http://dx.doi.org/10.5860/choice.32-5099.]

[26] Y. Saad, and M.H. Schultz, "GMRES: A generalized minimal residual algorithm for solving nonsymmetric linear systems", SIAM J. Sci. Statist. Comput., 1986.

[http://dx.doi.org/10.1137/0907058]

\section{C) 2021 Farooq \& Naqash.}

This is an open access article distributed under the terms of the Creative Commons Attribution 4.0 International Public License (CC-BY 4.0), a copy of which is available at: https://creativecommons.org/licenses/by/4.0/legalcode. This license permits unrestricted use, distribution, and reproduction in any medium, provided the original author and source are credited. 